\title{
PENERAPAN ELEKTROOSMOSIS UNTUK PENGERINGAN SLUDGE DARI PENGOLAHAN LIMBAH CAIR
}

\author{
$\operatorname{Darmawan}^{1 *}$, Dyah Tjahyandari Suryaningtyas ${ }^{1)}$, dan Juniska Muria Sariningpuri ${ }^{2)}$ \\ ${ }^{1)}$ Departemen Ilmu Tanah dan Sumberdaya Lahan, Fakultas Pertanian, IPB \\ Jl. Meranti, Kampus IPB Darmaga Bogor 16680. \\ ${ }^{2)}$ Alumni S1 Departemen Ilmu Tanah dan Sumberdaya Lahan, Fakultas Pertanian, IPB \\ ${ }^{*}$ Penulis korespondensi: darmawan_soil@yahoo.com
}

\begin{abstract}
APPLICATION OF ELECTROOSMOSIS FOR DEWATERING OF SLUDGE FROM WASTE WATER TREATMENT. Wastewater treatment produces semi-solid residue (sludge) that must be handled carefully during dumping and discharge to avoid polluting the environment. A low cost and easy treatment of dewatering is needed. This research aimed to apply electroosmosis technique for dewatering sludge in order to seek for parameters that can efficiently reduce water content of sludge, including range of voltage, type of electrodes, and distance between electrodes; and to determine the effect of electroosmosis processes on changes of chemical characteristics of sludge. The results showed that: (1) electroosmosis dewatering occurred on the sludge taken from waste water treatment of landfill but not on sludge from water purification plant (PDAM), (2) direct current voltage of 30 volts was the optimum voltage, (3) copper rod cathode provided electroosmosis process as good as stainless steel cathode and both were better than the woven stainless steel cathode, (4) the dewatering time to reduce $1200 \%$ (w/w) water content to about $400 \%$ was about 40 hours for sludge of $2500 \mathrm{~cm}^{3}$ in volume (laboratory bench scale), (5) the anode need to reinserted gradually approaching the cathode due to current lost when the water content at the anode point reached $400 \%$ and sludge at the point shrink, and (6) some chemical elements in the sludge decreased significantly after treatment.
\end{abstract}

Keywords: dewatering; electroosmosis; sludge; wastewater

\begin{abstract}
Abstrak
Pengolahan limbah cair menghasilkan residu berupa bahan semi padat yang dikenal sebagai sludge. Sludge tersebut juga perlu dikelola penyimpanan dan pembuangannya agar tidak mencemari lingkungan. Salah satu pengelolaan sludge yang perlu dilakukan adalah pengeringan (dewatering). Salahsatu teknik dewatering yang mungkin diterapkan ialah teknik elektroosmosis, yaitu teknik yang memanfaatkan adanya pergerakan air pada media poros di dalam medan istrik searah. Penelitian ini bertujuan untuk mencari parameter sistem dewatering secara elektroosmosis yang dapat menurunkan kadar air sludge paling efisien dan untuk mengetahui pengaruh elektroosmosis terhadap karakteristik kimia sludge. Hasil penelitian menunjukkan bahwa: (1) pengeringan sludge terjadi pada jenis sludge IPAL TPA namun tidak pada jenis lumpur PDAM; (2) tegangan listrik searah sekitar 30 volt merupakan tegangan optimum; (3) katoda batang tembaga menghasilkan proses elektroosmosis yang sebanding katoda batang stainless steel dan lebih baik dibanding katoda stainless steel anyam; (4) waktu pengeringan dari kadar air awal 1200\% (b/b) hingga kadar air akhir sekitar 400\% untuk volume sludge $2500 \mathrm{~cm}^{3}$ (skala laboratorium) sekitar 40 jam; (5) anoda perlu dipindahkan secara bertahap mendekati katoda karena arus terputus pada saat sludge di titik anoda mencapai kadar air sekitar 400\% dan mengalami pengerutan; dan (6) kadar beberapa unsur kimia dalam sludge menurun secara signifikan setelah perlakuan.
\end{abstract}

Kata kunci: dewatering; elektroosmosis; sludge; limbah

\section{PENDAHULUAN}

Pembuangan limbah baik dari kegiatan domestik maupun industri secara tidak terkendali dapat menyebabkan pengaruh buruk bagi lingkungan.
Terdapat 3 pendekatan dalam penanganan limbah untuk meminimalisasi pengaruh buruk dari unsurunsur atau senyawa-senyawa dalam limbah yaitu (1) menampung, menyimpan, menumpuk atau menimbun 
limbah pada areal yang didesain untuk menahan penyebaran limbah atau unsur-unsur atau senyawasenyawa limbah yang berbahaya, (2) menurunkan atau menghilangkan kadar unsur-unsur atau senyawasenyawa limbah yang berbahaya atau membuatnya imobil dan (3) menghilangkan atau mengubah bentuk limbah. Limbah padat dan kering seperti sampah rumah tangga, pasar maupun industri dapat dikelola dengan pendekatan pertama dan ke-tiga tersebut di atas. Sementara itu untuk limbah cair (sewage) seperti air buangan pabrik dan rumah tangga, air lindi tempat pembuangan sampah, dan lainnya perlu dikelola dengan pendekatan kedua. Oleh karena itu maka untuk pengelolaan limbah cair ini harus melalui sistem Instalasi Pengolahan Air Limbah (IPAL).

Hasil yang diharapkan dari pengolahan limbah cair ialah air yang dapat dialirkan ke perairan umum atau dimanfaatkan untuk berbagai tujuan. Namun demikian pada proses pengolahan limbah cair tersebut akan diperoleh endapan yang semi padat atau lumpur yang kepadatannya sangat bervariasi demikian pula volumenya. Lumpur ini atau yang dikenal sebagai sludge tidak dapat dibiarkan menumpuk di kolam pengendapan, karena volumenya akan terus bertambah sehingga kapasitas pengolahan limbah cair akan menurun. Selain itu sludge sangat mungkin mengandung unsur-unsur atau senyawa-senyawa yang berbahaya baik berupa atau di dalam partikel atau padatan atau berupa residu cairannya. Oleh karena itu, diperlukan pengolahan terlebih dulu yang bertujuan membersihkan atau mengurangi sludge dari unsurunsur dan senyawa-senyawa berbahaya, sekaligus mengeringkan sludge sebelum pemindahan agar volumenya susut dan lebih mudah diangkut dan ditumpuk (Tuan dkk., 2012a).

Teknologi untuk pengeringan (dewatering) dari sludge telah banyak dikembangkan, yaitu sentrifusi, pengepresan, penyaringan, dan pembakaran, yang memerlukan peralatan khusus dengan harga dan biaya pemeliharaannya mahal serta kapasitasnya terbatas. Teknologi lain yang mulai dikembangkan yang secara teknis dan ekonomis diprediksi prospektif ialah dengan memanfaatkan fenomena elektroosmosis (Tuan dkk., 2012a; Iwata dkk., 2013). Konsep dasar dari teknologi ini ialah menggiring molekul air yang menjadi bagian dari media porous melalui ruang antar partikel padatan (pori) menggunakan arus listrik dari anoda ke katoda sebagai flux sehingga air terdorong ke luar sistem (Acar dan Alshawabkeh, 1993; Liang, 1976). Arus listrik yang digunakan ialah arus searah dengan voltase rendah sehingga tidak berbahaya dan murah.

Pengembangan teknologi ini mengarah pada pemilihan konstruksi peralatan dan sistem kerja yang paling efisien, melalui pemilihan dan perangkaian elektroda yang awet dan murah, voltase yang sesuai, serta dimensi bak atau kompartemen yang sesuai. Penelitian ke arah ini masih relatif jarang (terutama di Indonesia). Selain aspek teknis yang masih perlu dikembangkan, dewatering secara elektroosmosis masih perlu dikaji ulang sehubungan dengan perubahan-perubahan yang mungkin terjadi terhadap komposisi kimia dan reaktifitas senyawa-senyawa yang masih tertinggal di dalam sludge pasca perlakuan pengeringan elektroosmosis tersebut, sebagai contoh Suryaningtyas dkk. (2005) mengungkapkan bahwa elektrokinetik (elektroosmosis dan elektromigrasi) mampu mengurangi kadar beberapa logam berat pada bahan overburden dari penambangan batubara.

Berdasarkan latar belakang tersebut di atas maka penelitian tentang pemanfaatan fenomena elektroosmosis untuk pengeringan sludge penting untuk dilakukan.

Adapun tujuan penelitian ini adalah untuk mencari parameter sistem dewatering secara elektroosmosis yang dapat menurunkan kadar air suldge paling efisien dan untuk mengetahui pengaruh elektroosmosis terhadap karakteristik kimia sludge.

\section{METODE PENELITIAN}

Secara umum penelitian terdiri dari tahap persiapan bahan dan alat, analisis karakteristik awal sludge, perlakuan elektroosmosis terhadap sludge, dan analisis karakteristik sludge pasca elektroosmosis. Perlakuan elektroosmosis dilakukan secara bertahap, yaitu: (1) perlakuan awal dengan menggunakan pasangan elektroda anoda dan katoda dan voltase yang berbeda dan (2) perlakuan elektrosmosis menggunakan pasangan elektroda terpilih dan sludge hasil akhir dianalisis.

Pelaksanaan percobaan elektrosomosis secara prinsip disajikan pada Gambar 1. Contoh sludge yang diketahui bobot, kadar air, dan volumenya ditempatkan pada kotak akrilik berukuran 30 x 10 x 10 $\mathrm{cm}^{3}$. Elektroda grafit sebagai anoda ditancapkan pada salah satu ujung sludge dan pada ujung sebaliknya ditancapkan elektroda positif. Kedua elektroda dihubungkan dengan sumber arus listrik searah (transformator) melalui suatu ampere meter. Selanjutnya arus listrik searah dengan voltase tertentu, yaitu 20, 30, atau 35 dialirkan selama periode tertentu hingga arus pada ampere meter menurun hingga mendekati nol. Tahap ini tergantung keadaan artinya waktu aliran tergantung perubahan arus, dan elektroda positif (anoda) digeser atau dipindah posisinya mendekati katoda secara bertahap ketika arus mendekati nol.

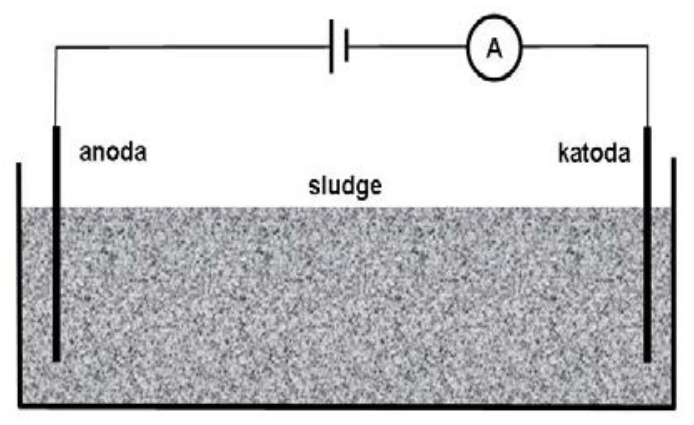

Gambar 1. Skema rangkaian alat elektroosmosis 


\section{HASIL DAN PEMBAHASAN}

\section{Karakteristik Sludge yang Digunakan}

Penelitian pengeringan secara elektroosmosis ini dilakukan dengan menggunakan dua jenis sludge, yaitu sludge dari IPAL TPA dan sludge dari tempat pengolahan air minum (PDAM). Karakteristik dari masing-masing sludge disajikan pada Tabel 1.

Sludge IPAL TPA mengandung senyawa organik tinggi, yang ditandai dengan kadar $\mathrm{C}$ sekitar $10 \%$ setara dengan $17-20 \%$ bahan organik dengan kadar abu sebesar 61.51\%. Sementara itu sludge PDAM didominasi oleh partikel-partikel mineral silikat yang halus atau dikenal sebagai partikel klei/clay (tidak ditunjukkan pada Tabel 1).

Tabel 1. Karakteristik sludge sebelum perlakuan elektroosmosis

\begin{tabular}{lrr}
\hline \multirow{2}{*}{ Parameter } & \multicolumn{2}{c}{ Jenis sludge } \\
\cline { 2 - 3 } Kadar air (\%) & IPAL TPA & \multicolumn{1}{c}{ PDAM } \\
pH & 1239 & 582 \\
EC (mS/cm) & 7.83 & 6.43 \\
$\mathrm{C}(\%)$ & 3.305 & - \\
$\mathrm{N}(\%)$ & 10.49 & 0.52 \\
$\mathrm{~S}(\mathrm{ppm})$ & 1.43 & - \\
$\mathrm{Fe}(\%)$ & 1.12 & - \\
$\mathrm{Mn}(\mathrm{ppm})$ & 0.18 & 101 \\
$\mathrm{Cu}(\mathrm{ppm})$ & 339.12 & 418.39 \\
$\mathrm{Zn}(\mathrm{ppm})$ & 23.22 & 0.86 \\
$\mathrm{Ca}$ & 24.85 & 0.05 \\
$\mathrm{Mg}$ & $0.18 \%$ & $105.67 \mathrm{ppm}$ \\
$\mathrm{Pb}(\mathrm{ppm})$ & $0.24 \%$ & $226.40 \mathrm{ppm}$ \\
$\mathrm{Cd}(\mathrm{ppm})$ & 9.38 & 0.04 \\
$\mathrm{~K}$ & 0.35 & 0.01 \\
$\mathrm{Na}$ & $1.30 \%$ & $1.68 \mathrm{ppm}$ \\
$\mathrm{P}$ & $2.36 \%$ & $12.60 \mathrm{ppm}$ \\
$\mathrm{Kadar} \mathrm{abu}(\%)$ & $6.36 \%$ & $28.41 \mathrm{ppm}$ \\
\hline & 61.51 & - \\
\hline
\end{tabular}

Isu penting dari limbah ialah mengenai kadar logam berat, seperti $\mathrm{Pb}$ dan Cd kadarnya di bawah 5 ppm kecuali $\mathrm{Cu}$ tergolong sangat rendah. Kadar unsur-unsur makro maupun mikro terutama Fe dan $\mathrm{Zn}$ untuk sludge IPAL TPA jauh lebih tinggi dibandingkan dengan sludge PDAM.

Tabel 1 juga menunjukkan bahwa EC dari sludge IPAL TPA lebih besar dibandingkan EC sludge PDAM. Hal ini berkaitan dengan komposisinya yang mengandung senyawa organik tinggi, kadar $\mathrm{Ca}, \mathrm{Mg}$, $\mathrm{K}$, Na, dan $\mathrm{P}$ yang jauh lebih tinggi dari sludge PDAM.

\section{Perbandingan Jenis Elektroda dan Voltase}

Jenis elektroda yang digunakan dalam elektroosmosis sangat penting karena berpengaruh terhadap besar kecilnya arus yang dapat mengalir. Selain itu jenis elektroda juga perlu dipilih berdasarkan ketahanannya terhadap korosi akibat perubahan $\mathrm{pH}$ yang drastis dari bahan yang diberi perlakuan elektroosmosis. Penelitian Darmawan dan Wada (2002) menunjukkan bahwa grafit merupakan pilihan untuk anoda sedangkan stainless steel dan tembaga merupakan pilihan untuk katoda.

Gambar 2, 3 dan 4 menunjukkan kisaran arus listrik yang mengalir di dalam sludge IPAL TPA selama aliran listrik DC sebesar 20, 30 dan 35 volt menggunakan pasangan elektroda yang berbeda. Secara umum arus listrik menurun tajam setelah beberapa jam dari pertama kali elektroda dihubungkan dengan sumber listrik. Ketika arus mendekati nol maka proses elektroosmosis untuk segmen sludge antara anoda dan katoda berjalan sangat lambat, sehingga anoda perlu digeser ke titik mendekati katoda. Berdasarkan besarnya arus maksimum yang dapat dicapai maka pasangan anoda batang grafit dan katoda tembaga serta pasangan anoda batang grafit dan batang stainless steel keduanya dapat dipertimbangkan sebagai pilihan.
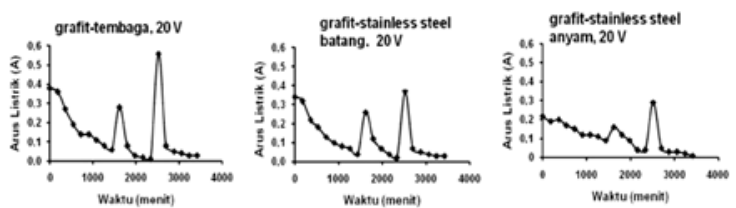

Gambar 2. Perubahan arus listrik (A) pada medium sludge pada voltase 20 volt DC pada tiga pasangan elektroda.

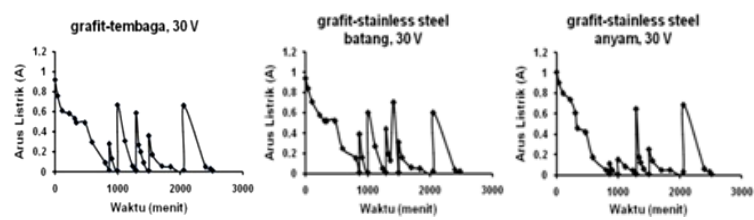

Gambar 3. Perubahan arus listrik (A) pada medium sludge pada voltase 30 volt DC pada tiga pasangan elektroda
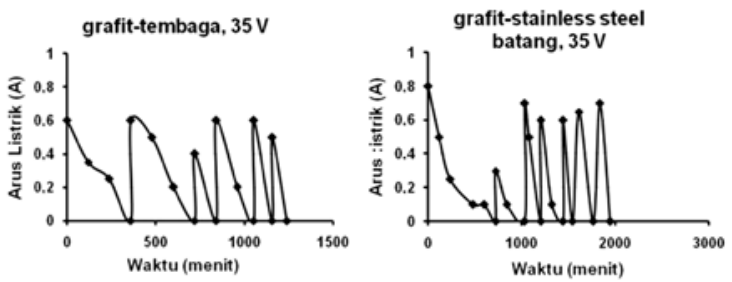

Gambar 4. Perubahan arus listrik (A) pada medium sludge pada voltase 35 volt DC pada dua pasangan elektroda

Pilihan jenis elektroda yang digunakan juga dapat didasarkan dari tingkat pengeringan yang dapat diperoleh. Gambar 5, 6, dan 7 menunjukkan perbandingan kadar air akhir setiap potongan sludge setelah elektroosmosis menggunakan pasangan elektroda yang berbeda. Percobaan elektroosmosis pada tahap pemilihan pasangan elektroda serta 
besarnya voltase ini menggunakan hanya satu jenis sludge yaitu sludge IPAL TPA yang sangat berair yaitu dengan persen kadar air (b/b) sebesar sekitar $1200 \%$. Setelah elektroosmosis pada tiap potongan segmen melintang dari sisi anoda ke arah katoda diketahui bahwa kadar air menjadi sekitar 400-600\% kecuali pada bagian yang dekat ke katoda. Hal ini juga dibuktikan dengan keluarnya efluen (leachate).

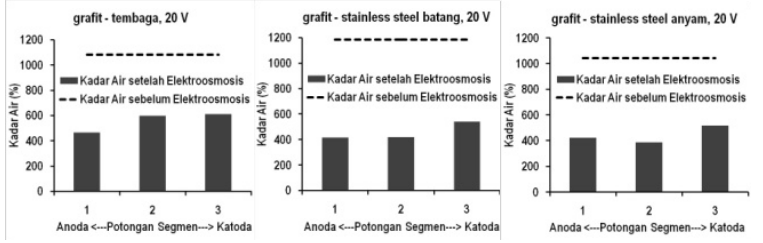

Gambar 5. Perubahan kadar air potongan segmen sludge setelah elektroosmosis pada voltase 20 volt DC pada tiga pasangan elektroda

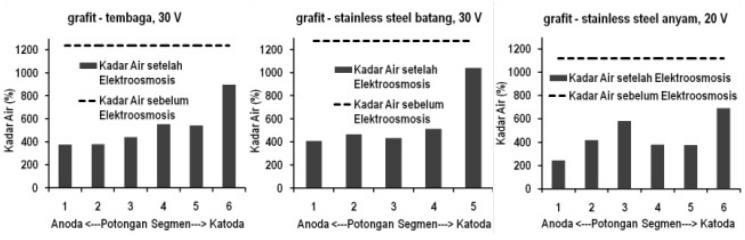

Gambar 6. Perubahan kadar air potongan segmen sludge setelah elektroosmosis pada voltase 30 volt DC pada tiga pasangan elektroda

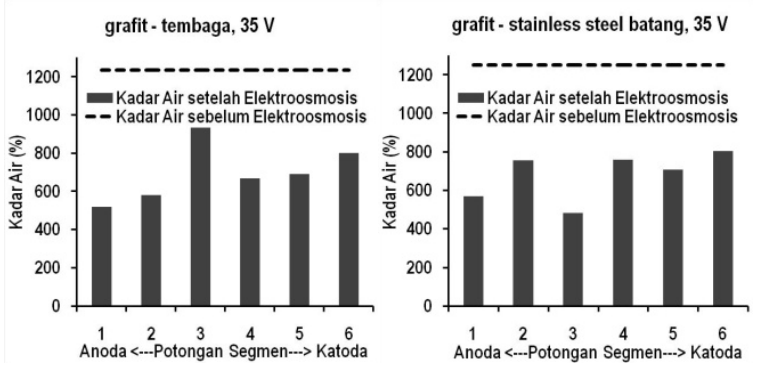

Gambar 7. Perubahan kadar air potongan segmen sludge setelah elektroosmosis pada voltase 35 volt DC pada dua pasangan elektroda.

Hal pertama yang dapat diinterpretasikan dari penurunan kadar air tersebut, bahwa teknik elektroosmosis mampu mengeringkan sludge dari jenis yang didominasi bahan organik namun memiliki EC yang relatif tinggi dan mengandung banyak unsur kation yang menentukan bekerja atau tidaknya proses elektroosmosis. Hasil ini sejalan dengan penerapan teknik elektrokinetik pada pengeringan sludge dari limbah industri di Taiwan (Chih dan Cing, 2002).

Kadar air akhir yang dapat diperoleh cukup menurun dibanding kadar air awal. Secara visual dari kondisi melumpur sludge berubah menjadi pasta yang relatif kering yang sudah mudah dipindah-pindah menggunakan alat-alat semacam cangkul ataupun sekop dan mudah ditebarkan di lahan terbuka tanpa menimbulkan pelumpuran atau leleran yang mengotori.

Dari data penurunan kadar air tersebut, dapat juga disimpulkan bahwa dengan menggunakan pasangan elektroda anoda batang grafit dan katoda batang tembaga menghasilkan penurunan kadar air yang lebih tinggi dibanding menggunakan pasangan lain.

\section{Peranan Waktu dan Jarak Antara Anoda dan Katoda}

Waktu yang dimaksudkan disini ialah waktu yang diperlukan dari awal aliran listrik hingga arus listrik dihentikan. Arus listrik dihentikan ketika besarnya arus telah mendekati nol, karena ini berarti bahwa aliran listrik tidak efektif lagi untuk menyebabkan terjadinya proses elektroosmosis. Dengan waktu yang sama maka dengan voltase 30 DC dan pasangan elektroda grafit-tembaga dan grafitbatang stainless steel diperoleh tingkat pengeringan yang lebih baik.

Penilaian peranan waktu yang lain ialah untuk mendapatkan gambaran berapa lama untuk suatu satuan volume atau jarak antara elektroda tertentu. Dalam penelitian skala laboratorium diperlukan waktu 2500 menit untuk mengeringkan masa sludge secara elektroosmosis yang berukuran $30 \mathrm{~cm}$, dengan lebar $10 \mathrm{~cm}$ dan tinggi $8 \mathrm{~cm}$. Namun perlu digaris bawahi bahwa dalam skala laboratorium atau miniatur ini ternyata anoda harus dipindah tempat secara periodik setiap kali terjadi atau tercapai penurunan arus mendekati nol. Fakta terputusnya arus dan mengharuskan menggeser anoda dengan frekuensi yang tinggi ini merupakan fakta yang jarang dijumpai pada publikasi hasil-hasil penelitian pengeringan bahan secara elektrosmosis.

\section{Perubahan Sifat-sifat Kimia Sludge Akibat Perlakuan Elektroosmosis}

Perubahan sifat sludge akibat perlakuan elektroosmosis yang diukur meliputi $\mathrm{pH}$, EC serta kadar unsur-unsur hara terekstrak air dan $\mathrm{HCl} 25 \%$. Hasil yang disajikan dalam makalah ini adalah kadar unsur-unsur yang terekstrak air, kecuali $\mathrm{Pb}, \mathrm{Cd}$ dan $\mathrm{P}$ yang disajikan dalam Gambar 8 hingga 12.

Data perubahan $\mathrm{pH}$ disajikan pada Gambar 8. Dari gambar ini terlihat bahwa perlakuan elektroosmosis yang menyebabkan reaksi elektrolisis air di anoda maupun di katoda menyebabkan $\mathrm{pH}$ di anoda menurun secara drastis dan di katoda meningkatkan cukup signifikan. Perubahan $\mathrm{pH}$ ini menyebabkan angka-angka ekstrim $\mathrm{pH}$ rendah dan tinggi. Hal ini merupakan kelemahan proses elektroosmosis, sehingga perubahan $\mathrm{pH}$ ini perlu menjadi bahan pertimbangan. Selain perubahan $\mathrm{pH}$ perlakuan elektroosmosis terhadap sludge juga menyebabkan perubahan EC. Jika dibandingkan dengan EC awal maka EC sludge menurun pada semua segmen kecuali pada potongan segmen yang dekat dengan katoda yang nilainya relatif sama dengan 
awal. EC yang masih tinggi pada ujung katoda berkaitan dengan kadar hidroksil yang tinggi dan garam-garam yang menumpuk pada ujung ini.
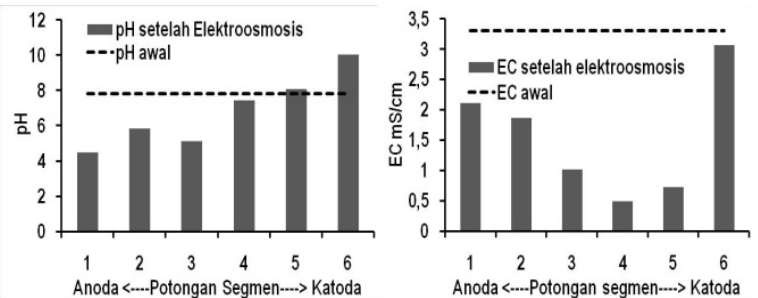

Gambar 8. Perubahan pH dan EC sludge IPAL TPA akibat elektroosmosis
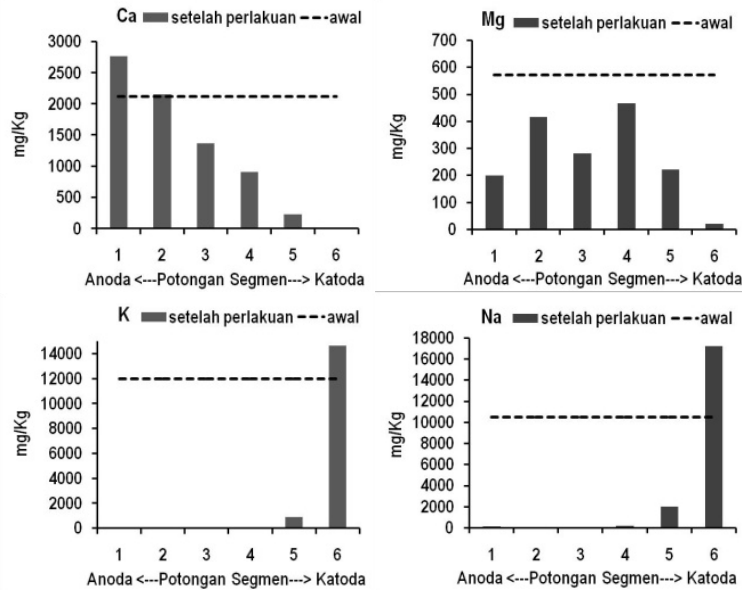

Gambar 9. Perubahan kadar Ca dan $\mathrm{Mg}, \mathrm{K}$, dan $\mathrm{Na}$ terekstrak air pada sludge IPAL TPA akibat perlakuan elektroosmosis

Perubahan kadar Ca, Mg, K, dan Na terekstrak air setelah perlakuan elektroosmosis disajikan pada Gambar 9. Kadar Ca terekstrak meningkat mendekati anoda. Hal ini kontradiktif dengan proses elektromigrasi kation di bawah medan listrik yang seharusnya bergerak menuju katoda untuk keluar dari sistem atau menumpuk dekat katoda. Sementara itu kadar $\mathrm{K}$ dan $\mathrm{Na}$ terekstrak air setelah perlakuan elektroosmosis jauh lebih kecil dibanding awal kecuali pada ujung katoda dimana terjadi penumpukan karena $\mathrm{KOH}$ dan $\mathrm{NaOH}$ larut dalam air.

Selanjutnya berdasarkan Gambar 10 dapat dilihat perubahan kadar unsur makro $\mathrm{Fe}, \mathrm{Mn}, \mathrm{Cu}$ dan Zn yang diekstrak dengan air. Kadar awal Fe setelah perlakuan elektroosmosis menurun tajam. Hal ini cukup menguntungkan jika sludge pasca elektroosmosis akan digunakan sebagai bahan pembenah tanah. Untuk unsur-unsur mikro Fe dan Zn cukup signifikan menurun sementara $\mathrm{Cu}$ dan juga $\mathrm{Mn}$ tampak masih menumpuk di ujung katoda, Pergerakan ion-ion yang bermigrasi ke katoda yang bereaksi alkalin akan mengalami imobilisasi melalui reaksi adsorpsi dan presipitasi (Roach dkk., 2009).
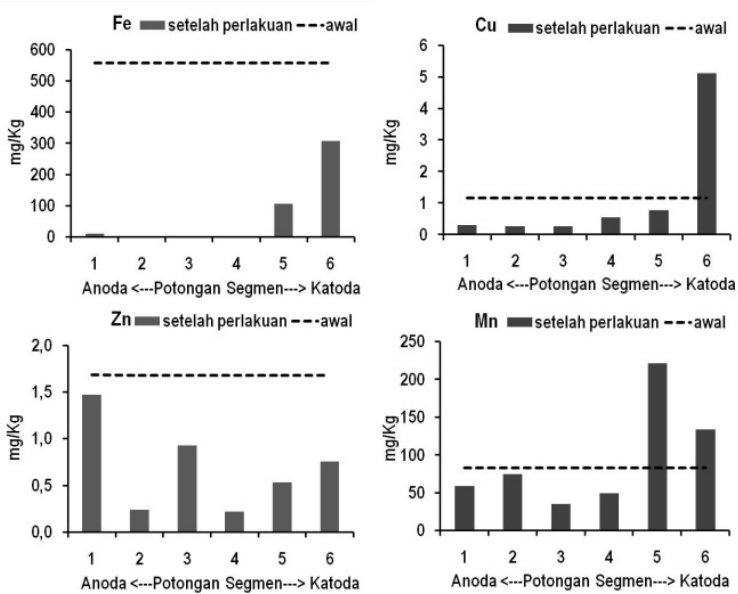

Gambar 10. Perubahan kadar Fe, Cu, Mn, dan Zn terekstrak air pada sludge IPAL TPA akibat perlakuan elektroosmosis
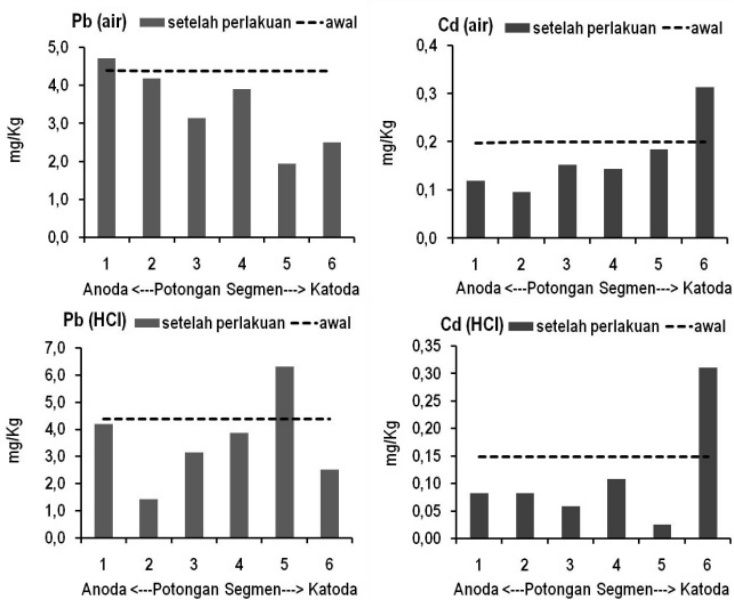

Gambar 11. Perubahan kadar Pb dan Cd terekstrak air dan $\mathrm{HCl} 25 \%$ pada sludge IPAL TPA akibat perlakuan elektroosmosis

Gambar 11 menunjukkan perubahan kadar logam berat $\mathrm{Pb}$ dan $\mathrm{Cd}$ yang terkandung dalam sludge. Dari gambar tersebut tampak terjadi penurunan yang berarti dari kadar $\mathrm{Pb}$ dan $\mathrm{Cd}$ baik yang terekstrak oleh air maupun $\mathrm{HCl} 25 \%$, walaupun masih terlihat penumpukan di katoda. Hal ini menunjukkan bahwa untuk penanganan sludge yang mengandung logam berat seperti $\mathrm{Pb}$ dan $\mathrm{Cd}$ yang tinggi maka bagian ujung katoda perlu ditangani secara khusus.

Gambar 12 menunjukkan perubahan kadar $\mathrm{P}$ pada sludge akibat perlakuan elektroosmosis. Sludge yang digunakan mengandung unsur $\mathrm{P}$ yang kemungkinan berupa senyawa fosfat yang cukup tinggi. 


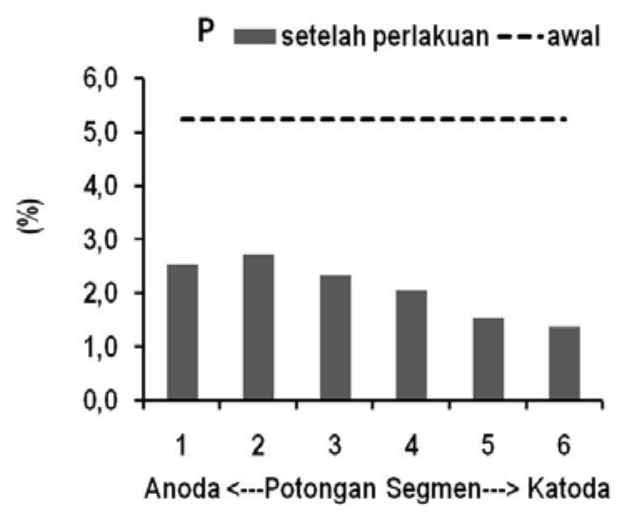

Gambar 12. Perubahan kadar P terekstrak HCl 25\% pada sludge IPAL TPA akibat perlakuan elektroosmosis

Pembuangan limbah ini apa adanya apalagi dalam keadaan melumpur ke tempat-tempat terbuka akan mencemari lingkungan dilihat dari kadar $\mathrm{P}$ ini yang jika terlarut ke badan perairan umum akan menyebabkan eutrofikasi. Penurunan kadar yang terjadi akibat elektroosmosis mencapai kira-kira setengah dari kadar awal.

\section{Percobaan Pengeringan Elektroosmosis Terhadap Sludge PDAM}

Seluruh hasil yang dijelaskan di atas diperoleh dari percobaan menggunakan sludge IPAL TPA. Sementara itu percobaan dengan jenis sludge yang sama sekali lain, yaitu sludge PDAM ternyata tidak menunjukkan hasil yang baik dalam arti tidak terjadi proses elektroosmosis yang diharapkan, ditunjukkan dengan arus listrik yang sangat kecil (Gambar 13). Hal ini disebabkan karena EC dari sludge tersebut sangat rendah. Jumlah dan arah aliran elektroosmosis tergantung pada jenis elektrolit (Ahmad dkk., 2006; Tuan dkk., 2012b).

\section{KESIMPULAN}

Berdasarkan hasil percobaan maka diperoleh beberapa kesimpulan sesuai dengan tujuan penelitian ini, yaitu bahwa pengeringan sludge secara elektroosmosis terjadi pada jenis sludge IPAL TPA namun tidak pada jenis lumpur PDAM. Tegangan listrik searah 30 volt merupakan tegangan optimum. Katoda batang tembaga menghasilkan proses elektroosmosis yang sebanding dengan katoda stainless steel dan lebih baik dibanding katoda stainless steel anyam.

Waktu pengeringan dari kadar air awal 1200\% hungga kadar air akhir sekitar 400\% sekitar 40 jam pada laboratorium. Diperlukan pemindahan anoda secara bertahap karena arus terputus pada saat sludge mencapai kadar air sekitar 400\%, dan juga akibat sludge mengalami pengerutan.

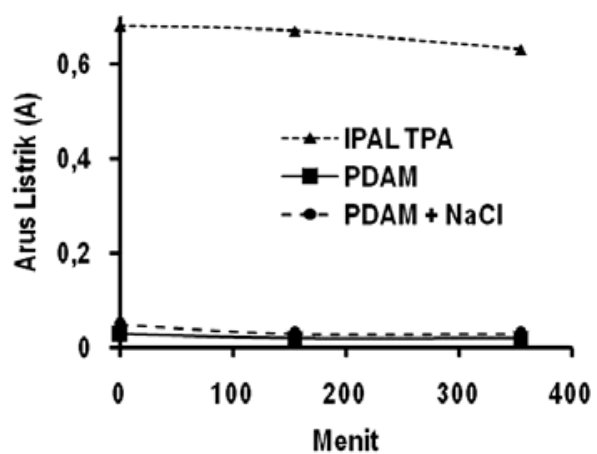

Gambar 13. Perbandingan besar arus pada jarak antar elektroda $25 \mathrm{~cm}$ antara perlakuan elektroosmosis pada sludge IPAL TPA, PDAM dan PDAM ditambah elektrolit $10 \mathrm{mMol} \mathrm{NaCl}$

Secara umum kadar unsur-unsur dalam sludge menurun secara signifikan terutama pada bagian yang jauh dari katoda.

\section{UCAPAN TERIMA KASIH}

Penulis mengucapkan terimakasih kepada Dirjen Pendidikan Tinggi, Kementerian Pendidikan dan Kebudayaan atas bantuan dana berupa Hibah Fundamental. Ucapan terima kasih disampaikan juga kepada Pimpinan TPA Bantar Gebang dan Direktur PDAM Tirta Pakuan Kota Bogor atas ijin yang diberikan untuk pengambilan sludge.

\section{DAFTAR PUSTAKA}

Acar, Y.B. and Alshawabkeh, A.N., (1993), Principles of Electrokinetic Remediation, Environ. Sci. Technol., 27, pp. 2638-2647.

Ahmad, K., Kasim, K.A., and Taha, M.R., (2006), Electroosmotic Flows and Electromigrations During Electrokinetic Processing of Tropical Residual Soils, Malaysian Journal of Civil Engineering, 18(2), pp 7488.

Darmawan and Wada, S.-I., (2002), Effect of Clay Mineralogy on the Feasibility of Electrokinetic Soil Decontamination Technology, Applied Clay Science, 20, pp. 283-293.

Iwata, M., Tanaka, T., and Jami, M.S., (2013), Application of Electroosmosis for Sludge Dewatering - A Review, Drying Technology, 31(2), pp. 170-184.

Liang, L.-S., (1976), Electroosmotic Dewatering of Wastewater Sludges, Disertasi, Massachusetts of Technology, USA.

Panjaitan, N.H., Rifai, A., Adi, A.D., and Sumardi, P., (2012), The Phenomenon of Electromigration During Electrokinetic Process on Expansive Clay Soil, IJCEE-IJENS, 12(4), pp. 47-50. 
Roach, N., Reddy, K.R., and Al-Hamdan, A., (2009). Particle Morphology and Mineral Structure of Heavy Metal-Contaminated Kaolin Soil Before and After Electrokinetic Remediation, Journal of Hazardous Materials, 165, pp. 548-557.

Suryaningtyas, D.T., Firosya, A. dan Darmawan, (2005), Pemanfaatan Air Asam Tambang dalam Teknik Elektrokinetik untuk Menurunkan Kadar Logam Berat Bahan Timbunan Bekas Tambang, Reaktor, 9(2), hal.100-106.
Tuan P.A., Isosaari, P., and Sillanpää, M., (2012a). Sewage Sludge Electro-Dewatering Treatment-A Review, Drying Technology, 30(7), pp. 691-706.

Tuan P.A., Isosaari, P., and Sillanpää, M., (2012b), Effect of Polyelectrolyte Conditioning and Voltages on Fractionation of Macro and Trace Metals due to Sludge Electro-Dewatering, Separation Science and Technology, 47(6), pp. 788-795.

Weng, C. H. and Yuan, C., (2002), Enhancement of Sludge Dewatering: Application of Electrokinetic Technique, Journal of the Chinese Institute of Environmental Engineering, 12(3), pp. 235-243. 